\title{
ICT Infrastructural and Technical Challenges: A Major Impediment towards the Development of Open and Distance Learning (ODL) in Nigeria
}

\author{
Igboeli Uchenna $\mathbf{H}$. \\ Learner Support \\ Department of CDL \& CE, University of Abuja, Nigeria \\ uchenna.igboeli@uniabuja.edu.ng \\ Bisallah Hashim I. \\ Senior Researcher \\ Department of Computer Science, University of Abuja, Nigeria
}

\begin{abstract}
In the fast-growing population of Africa, Nigeria has become the most populous nation with over 177,000,000 inhabitants and consisting of about 32\% youths (Abdulrahman et al, 2014). Sustainable development can only be achieved through proper education at all levels. While the regular classroom-based educational programmes have been characterized by incessant strikes and ever-increasing requests for admission due to increasing population, the introduction and acceptance of Open and Distance Learning programmes (ODL) as an alternative to classroom based system, has become imperative to cater for the educational needs of the entire citizenry. Although there have been considerable investments in educational facilities in most schools offering ODL programmes, this research found that a lot still need to be put in place, considering that that high cost of internet access, tutor-learner relationship, educational tools and the packaging of ODL educational resources continues to pose tremendous challenges to students thereby affecting their learning rates and by extension, their academic performance.
\end{abstract}

Keywords: ODL, ICT, Independent Study, Open Access, Blended Learning

\section{Introduction}

The primary objective of distance learning is to create alternative learning paths for people to study regardless of geographic, socio-economic or other associated constraints (UNESCO, 2002). Initially, vast candidates and students of distance learning programmes are gainfully employed adults seeking to either improve their working skills and seek better conditions of service or even develop new skills and make a career shift. Today, distance learning in Nigeria has witnessed a massive boost by youths who are not privileged to secure admission in regular classroom-based programmes. The 'Openness' in distance learning makes it possible for a vast number of students to participate in the program irrespective of distance, time and culture which have often created major setbacks on regular programmes. 
Massive open online courses (MOOCs), aimed at large-scale interactive participation and open access via the web or other network technologies, are a recent development in distance education (Wiki, 2014). Increasingly more open universities are using various levels of technologies to drive their programmes. In recent years, the world has adopted the use of technologies for service delivery and the academic environment is not left out in the move. New terminologies have continued to evolve including e-learning, online learning, blended learning and virtual learning to mean that the learner uses a variety of media, not just computers, to learn. These are different forms of distance learning. With the recent introduction of blended learning, ODL is now being mixed with conventional classroom-based teaching to drive content and ensure quality of learning without compromising flexibility and demands of work and culture. ODL have ensured that most of the stumbling blocks and restrictions placed on conventional programmes have been limited if not completely eroded. The role played ICT in distance learning have limited the barriers placed by religious and cultural belief system as students barely have face-to-face contact with facilitators. However, with the rapid expansion of ICTs, it is expected that technology-based educational applications could be fused to school-based programmes though there is every possibility that many unprivileged ones many be left behind due to scarcity of resources (Situma, 2015).

\subsection{Objective of the Research}

This research aims to investigate the challenges faced by ODL students and their facilitators in the quest for knowledge and the delivery of acceptable standards in our academic institutions. Since ICT is an indispensible tool in ODL, it becomes paramount that the challenges militating the development of this system of education in Nigeria be properly examined with the aim of proffering solutions for sustainable development and academic excellence.

\subsection{Significance of the Research}

ODL offers a number of benefits to both learners and facilitators and providers of opportunities for learning even while contributing at workplace. Problems of distance and time, which are barriers to conventional face-to-face learning, are overcome in ODL (COL, 2000). 
The study and analysis of the ICT challenges in the delivery of ODL education will be of utmost benefit to education managers, students and prospecting students in a number of ways:

- This will enable the government and education managers to plan towards human capacity development in education using ICT

- Adequate provision and investment in the educational sector as a means towards actualizing the Agenda for Sustainable Development

- Taking care of the educational needs of the increasing population in Africa generally since all cannot afford the classroom-based program.

- Preparing the prospecting ODL students towards the challenges they will be facing in the new study pattern

\subsection{Research Hypothesis}

This research is based on the following statistical hypothesis:

$\mathrm{H}_{0}$ : There is no relationship between the level of ICT Infrastructure in Nigeria and the administration of ODL.

$\mathrm{H}_{1}$ : Robust investment in ICT in Nigeria is a crucial element for ODL education and performance enhancement.

\section{Literature Review}

It is a globally accepted fact that education plays a vital role in national development which cannot be replaced by any other aspect of life. All the nations of the world seem to respond to the fundamental arguments that make education an integral part of national development. This has been the trend as most nations of the world, including government agencies and their respective citizens have keyed into this fact to make their nations great. Unfortunately, in most developing countries especially in Africa, the implementation of laid down rules and procedures has become a nightmare for many while for others, the hap-hazard policy formulation and execution, coupled with either the absence or the lack of enforcement of ineffectual, laws and regulatory activities to guide educational development has been an impediment (Jegede, 2014). 
National Policy on Education was published in 1997 along with various editions all aimed at keeping with the dynamics of social cum cultural changes and the demands on education. The 4th edition was necessitated by some policy innovations and changes, and the need to update the 3rd edition (1998) accordingly. Some of these innovations and changes include:-

- The lifting of the suspension order on Open and Distance Learning Program by Government.

- Revitalization and expansion of the National Mathematical Centre (NMC).

- Establishment of the Teachers Registration Council (TRC).

- Introduction of ICT into the school curriculum as a second official language

Adesina (1977) is of the view that implementation of all relevant plans are usually constrained by the following factors:-

- Over-estimation of available resources - This comes to play when estimated resources are greater than available resources available to implement a program.

- Under-estimation of the costs of implementing a plan - Occurs when cost-estimates fail to make adequate provisions for inflation thereby leading to unmanageable actual implementation costs.

- Over-reliance upon external assistance - Plans that rely upon assistance from foreign or borrowed sources for their implementation which may run into hitches when such aid fails to come.

- Inaccurate statistical data - Educational Planning requires accurate and up-to-date data collected and stored by well-informed personnel for the purpose of forecasts and projections.

Okoroma (2006) stressed that the spirit and enthusiasm with which Nigerians accepted and embraced the National Policy on Education has died down due to non-performance. The enormous expectations that greeted the Nigeria public and the hopes and aspirations of the populace have been compromised by policy makers and implementation managers. The flexibility and organizational framework of ODL by design, is expected to service people of diverse categories ranging from undergraduate students to working professionals. This is expected to enable them to contribute to the development of qualified African work force. Edu et al. (2016) in a research on the ODL and Challenges on Quality, noted that ICT remains a key factor in ensuring quality in 
ODL operations. The quality of the educational materials and other resources made available to ODL students will however, determine the quality of education that will be received by the students. This study also emphasized on the role of educational managers in-charge of preparation of course materials to ensure that the resources adhere strictly to ODL standards so as to make learning easy to students. E-learning did not evolve to be a substitute the physical classroom learning in higher institutions (Iloanusi, 2007). However, the goal of this study mode is to enhance learning and efficient delivery of knowledge to widely dispersed population who can study at their own pace and still acquire the same level of education with their counterparts using the classroombased model.

The study by Jegede (1999) shows the progression of various methods of ODL delivery from the $16^{\text {th }}$ century till date. This work clearly indicates the continuous adaptation of ODL to the technology of the day, starting from the days of using the print-only methods of correspondence learning to the introduction of multimedia and smart devices of this century. The ability of both the facilitators and the students to attain the full benefits of ODL and harness the factors driving the ODL move is partially a function of their ICT knowhow. Tichaona \& Mufunani (2015) in a similar research found that most ODL students and teachers do not seem to have sufficient knowledge of ICT and essential skills needed to enable them to attain the efficacy of ICT in enhancing quality ODL teaching and learning. The authors therefore recommend the need for Andragogic ICT Model (ADIM), which suggests a different and peculiar ways of teaching adults all so as to raise the quality of ODL. Karsenti \& Collin (2012) in a research on examining the role of ICT in ODL, came to the conclusion that ODL programmes not only have high roles to play for the future of Africa, but have even fulfilled some of its promises to some reasonable extent. The work however suggests that to advance ODL in Africa, it would be useful to facilitate some form of adjustments to ODL programmes. This adjustment includes proactive information sessions prior to enrollment so that students knows ahead of time what to expect from the program and what will be required of them coupled with the meaning and mechanisms of ODL. It will also include the technological aspects such as platforms and software. Understanding of the use of ICT and smart devices even before enrolment into ODL programmes will go a long way towards taking care of some of the peculiar needs of ODL students at all levels.

ODL can however provide the needed access for academic enthusiasts who have in one way or the other been disadvantaged through the conventional educational system. The peculiarity 
of the ODL and its challenges such as inconsistency in policy implementation and technological deficiencies have a lot of bearing on the result-oriented operation of ODL efficient and effective lesson delivery in Nigeria (Ogbeide, 2019). The researcher specifically suggested that ODL system should be redesigned to make use of a combination of conventional resources and ICT techniques shifting gradually to complete ICT-based programmes. Poor ICT infrastructure, epileptic power supply, inconsistent policy formulation, poverty and several other factors account for the low penetration of ODL in most parts of Africa as ODL cannot thrive where these factors are prevalent due to its nature and form of delivery.

While some researchers are of the opinion that there exists some differences in learning outcomes between classroom-based and distance learning programmes, Kanwar \& Cheng (2017) found that there is little or no difference between the effectiveness of face-to-face and online methods of content delivery. However, there is significant cost-saving when compared to the faceto-face training as ODL and e-learning generally are cheaper. In terms of quality, the researcher also stated that the Open University ranks among the top ten universities in the United Kingdom in terms of student satisfaction and are equally high in global rankings for research, innovation and use of ICTs. These arguments have accounted for continued growth in the number of enrolments in ODL in recent years almost in every country in Africa. The role of ICT in the propagation and actualization of the desired goals of ODL seem to be same worldwide. The distant nature of the program makes it important and necessary that students and facilitators have to be in constant communication via a connection oriented medium for teaching and learning. However, Isuku (2018) came to the conclusion that despite the tremendous benefits derived from the use of ICT facilities in ODL, the challenges facing students in the program can overwhelm the benefits if appropriate policies are not formulated. The study revealed that some of the major challenges facing access to ODL programmes in Nigeria include epileptic power supply (28.57\%), high cost of ICT facilities (24.4\%), poor Internet connectivity $(21.95 \%)$ in addition to poor mobile data network signal (23.4\%). The result from this study is in line with what is obtainable in most underdeveloped countries of Africa. In Nigeria with a population of over 200 million people with $23.10 \%$ unemployment rate and a minimum wage of about $\$ 75$ monthly (Trading Economics, 2018), the average working class finds it difficult to afford an average computer of $\$ 200$. The quest for education and flexible learning environment should not be a reason to compromise on quality however. Modesto and Gregoriose (2016) insist that quality, relevance, access, excellence, 
innovation, governance, and student-centeredness ought to be adhered to more consciously, more proactively, and more systemically among other factors.

\section{Methodology}

In this research, the use of questionnaires was primarily adopted. This allowed the respondents who are primarily ODL students in three universities in Nigeria to feel free to air their views without being influenced by the researcher. The questionnaire adopted the use of closeended questions with bounded responses. In this research, 530 questionnaires were administered comprising of various sections. The sections include:

- ICT Infrastructure

- Use of Internet

- Barriers on the use of ICT and Internet Services

- Challenges on the use of ICT and ODL

\subsection{Population and Sampling}

The questionnaires were managed by the researchers without sponsorship from any organization, group or individual(s) with all the attendant constraints of time and cost. This justified the adoption of convenient sampling technique in the study (Hussain, Cakir \& Candeğer, 2018). The sample is made up of a combination of respondents from National Open University of Nigeria (NOUN), Centre for Distance Learning and Continuing Education (CDL\&CE) University of Abuja and Nasarawa State University Keffi Distance Learning Program. Out of the 530 questionnaires administered, 511 of them were returned and fully completed.

\subsection{Tool for Data Collection}

The research is majorly a quantitative study of a descriptive and exploratory nature. The questionnaires used were prepared according to the objectives and nature of the study. The tools were validated through their pilot testing on 50 students of the CDL \& CE and 15 ODL facilitators with the expert's opinion. After some modifications and rephrasing of questions and statements, the final set of questions were subjected to a reliability test and a reliability coefficient of 0.82 was obtained.

\subsection{Procedure of Data Collection and Implementation of Research Tools}


Data were collected with the help of various courses representatives in the three institutions used in the study. These representatives were trained by the principal researchers on the procedure to be used in the assignment. The respondents participated in the survey on volunteer basis. The participants were being briefed about the study and procedure of data collection by the data collectors. The confidentiality of the data was also ensured to the participants of the study. The tool was administered on 530 Students with 511 (96.4\%) successfully completed and collected.

\subsection{Data Analysis Techniques}

On completion of the data collection process, all data were entered into a coded Microsoft Excel sheets already coded with parameters corresponding to the questionnaires. The data were exported to Statistical Package for Social Sciences (SPSS) which was used for the analysis. Data analysis was performed using simple averages and chi-square technique to test the hypothesis. The justification for the use of chi-square distribution, with k-1 degrees of freedom, where $\mathrm{k}$ is the number of categories, is driven by the fact that the responses fall into categorical data.

\section{Data Analysis}

Table 1: Cross tabulation of Level of ICT infrastructure in Students' Area of Residence and Cost of Internet Access with his Provider

\begin{tabular}{|c|c|c|c|c|c|c|}
\hline & \multicolumn{3}{|c|}{$\begin{array}{l}\text { Cost of Internet Access } \\
\text { Provider (WWW5) }\end{array}$} & \multirow[b]{2}{*}{ Total } \\
\hline & & & $\begin{array}{l}\text { Very } \\
\text { High }\end{array}$ & High & Moderate & \\
\hline \multirow{12}{*}{$\begin{array}{l}\text { Level of ICT } \\
\text { Infrastructure } \\
\text { in area of } \\
\text { residence } \\
\text { (ICT1) }\end{array}$} & \multirow[t]{4}{*}{ Low } & Count & 75 & 65 & 8 & 148 \\
\hline & & $\%$ within ICT1 & $50.7 \%$ & $43.9 \%$ & $5.4 \%$ & $100.0 \%$ \\
\hline & & \% within WWW5 & $29.8 \%$ & $29.3 \%$ & $21.6 \%$ & $29.0 \%$ \\
\hline & & $\%$ of Total & $14.7 \%$ & $12.7 \%$ & $1.6 \%$ & $29.0 \%$ \\
\hline & \multirow[t]{4}{*}{ Medium } & Count & 126 & 107 & 22 & 255 \\
\hline & & $\%$ within ICT1 & $49.4 \%$ & $42.0 \%$ & $8.6 \%$ & $100.0 \%$ \\
\hline & & $\%$ within WWW5 & $50.0 \%$ & $48.2 \%$ & $59.5 \%$ & $49.9 \%$ \\
\hline & & $\%$ of Total & $24.7 \%$ & $20.9 \%$ & $4.3 \%$ & $49.9 \%$ \\
\hline & \multirow[t]{4}{*}{ High } & Count & 51 & 50 & 7 & 108 \\
\hline & & $\%$ within ICT1 & $47.2 \%$ & $46.3 \%$ & $6.5 \%$ & $100.0 \%$ \\
\hline & & $\%$ within WWW5 & $20.2 \%$ & $22.5 \%$ & $18.9 \%$ & $21.1 \%$ \\
\hline & & $\%$ of Total & $10.0 \%$ & $9.8 \%$ & $1.4 \%$ & $21.1 \%$ \\
\hline \multirow{3}{*}{\multicolumn{2}{|c|}{ Total }} & Count & 252 & 222 & 37 & 511 \\
\hline & & $\%$ within ICT1 & $49.3 \%$ & $43.4 \%$ & $7.2 \%$ & $100.0 \%$ \\
\hline & & $\%$ within WWW5 & $100.0 \%$ & $100.0 \%$ & $100.0 \%$ & $100.0 \%$ \\
\hline
\end{tabular}




\begin{tabular}{|l|l|l|l|l|l|}
\hline & \% of Total & $49.3 \%$ & $43.4 \%$ & $7.2 \%$ & $100.0 \%$ \\
\hline
\end{tabular}

The table 1 above shows a cross-tabulation analysis of the level of ICT infrastructure in the student's area of residence viz-a-viz the cost of internet access with their respective providers. It is evident that less than $7.5 \%$ of the sample is of the opinion that the cost of internet access which is a major player in the administration ODL is moderate. In as much as cost of internet access differs from provider to provider with some of them offering some mouth-watering bonuses, the ability of maintain a stable connection of those fairly cheap providers in most areas is a major hindrance. The people will have no other choice than to use the more expensive ones. This is also evident in the $29.0 \%$ level of infrastructure obtained from the result. This low level of infrastructure is mostly applicable in the remote areas where the service providers do not perceive to make sufficient profit from. This have caused great hindrance to students in some of those remote areas especially when attending online classes and uploading of heavy documents.

Table 2: Frequency table for Lack of understandable ODL Learning Materials

\begin{tabular}{|l|l|r|r|r|}
\hline \multicolumn{2}{|c|}{} & Respondents & Valid Percent & Cumulative Percent \\
\hline \multirow{3}{*}{ alid } & No & 151 & 29.5 & 29.5 \\
\cline { 2 - 5 } & Yes & 206 & 40.3 & 69.9 \\
\cline { 2 - 5 } & Somehow & 154 & 30.1 & 100.0 \\
\cline { 2 - 5 } & Total & 511 & 100.0 & \\
\hline
\end{tabular}

Table 2 is a frequency table of the measure of the influence of preparation and packaging of ODL materials as a challenge to the students' acceptability and performance. It is shown that there is still a lot of work to be done in the way the education resources are presented and packaged. About $40 \%$ of the respondents indicated that they are having issues with understanding the learning materials while about 30\% are indifferent in the way and manner these materials are presented.

Table 3: Frequency Table for Availability of Facilitators as a Challenge

\begin{tabular}{|l|l|r|r|r|}
\hline \multicolumn{2}{|c|}{} & Respondents & Valid Percent & Cumulative Percent \\
\hline \multirow{3}{*}{ Valid } & No & 166 & 32.5 & 32.5 \\
\cline { 2 - 5 } & Yes & 194 & 38.0 & 70.5 \\
\cline { 2 - 5 } & Somehow & 151 & 29.5 & 100.0 \\
\cline { 2 - 5 } & Total & 511 & 100.0 & \\
\hline
\end{tabular}

Table 3 captures the availability of facilitators as a challenge to ODL in Nigeria. The analysis shows no clear difference in the position of the students in this regard. It shows that the students are of the belief that if the materials are clear and comprehensive enough, the availability 
of the facilitators may not pose a major challenge to their learning ability and academic performance.

Table 4: Frequency Table for Unfriendly Tutors as a Challenge

\begin{tabular}{|l|l|r|r|r|}
\hline \multicolumn{2}{|c|}{} & Respondents & Valid Percent & Cumulative Percent \\
\hline \multirow{3}{*}{ Valid } & No & 42 & 8.2 & 8.2 \\
\cline { 2 - 5 } & Yes & 236 & 46.2 & 54.4 \\
\cline { 2 - 5 } & Somehow & 233 & 45.6 & 100.0 \\
\cline { 2 - 5 } & Total & 511 & 100.0 & \\
\hline
\end{tabular}

Table 4 measures the level of friendliness of the tutors while relating to the learners. It is worth noting that the level of friendliness and the cordial relationship between tutors and learners have a direct on the psychology of the students and by implication, their performance. In a study on Students' Learning Characteristics, Evangelia \& Noel (2019) found that students have a special way of describing teachers who are accessible as having exceptional qualities and character which include tolerating ambiguity, showing authenticity and empathy, providing opportunities for discussion in breaks, and offering thinking spaces within class through which students feel free to follow their own lines of enquiry within the expected disciplinary discourse. In this research, it is evident that only $8.2 \%$ of students do not see the level of unfriendliness of the tutors as a challenge.

Table 5: Frequency Table for Expensive Data Cost as a Challenge

\begin{tabular}{|l|l|r|r|r|}
\hline \multicolumn{2}{|c|}{} & Respondents & Valid Percent & Cumulative Percent \\
\hline \multirow{3}{*}{ Valid } & No & 29 & 5.7 & 5.7 \\
\cline { 2 - 5 } & Yes & 371 & 72.6 & 78.3 \\
\cline { 2 - 5 } & Somehow & 111 & 21.7 & 100.0 \\
\cline { 2 - 5 } & Total & 511 & 100.0 & \\
\hline
\end{tabular}

Table 5 examines the perception of the students on the cost of data as a challenge. The response obtained is alarming when compared to acceptability of ODL as a means of reducing the academic gap between people who by one reason or the other could not attend the conventional face-to-face university education and their privileged counterparts. Only about $6 \%$ of the sample does not see the cost of data as a challenge while about $73 \%$ are of the view that the cost of data has adverse effect and affecting their day-to-day educational requirements. Caution however, have to be taken in this conclusion as a similar work on the relationship between the students' CGPA and data usage shows there is no direct correlation between Data Usage with CGPA (Senthil, 2018). 
Table 6: Cross Tabulation of Lack of understandable learning materials and Unfriendly Tutors as Challenges to ODL

\begin{tabular}{|c|c|c|c|c|c|c|}
\hline & \multicolumn{3}{|c|}{$\begin{array}{l}\text { Unfriendly Tutors } \\
\text { (CHA3) }\end{array}$} & \multirow[b]{2}{*}{ Total } \\
\hline & & & No & Yes & Somehow & \\
\hline \multirow{12}{*}{$\begin{array}{c}\text { Lack } \\
\text { of } \\
\text { understandabl } \\
\text { e learning } \\
\text { materials } \\
\text { (CHA1) }\end{array}$} & \multirow[t]{4}{*}{ No } & Count & 10 & 74 & 67 & 151 \\
\hline & & $\%$ within $\mathrm{CHA} 1$ & $6.6 \%$ & $49.0 \%$ & $44.4 \%$ & $100.0 \%$ \\
\hline & & $\%$ within $\mathrm{CHA} 3$ & $23.8 \%$ & $31.4 \%$ & $28.8 \%$ & $29.5 \%$ \\
\hline & & $\%$ of Total & $2.0 \%$ & $14.5 \%$ & $13.1 \%$ & $29.5 \%$ \\
\hline & \multirow[t]{4}{*}{ Yes } & Count & 24 & 94 & 88 & 206 \\
\hline & & $\%$ within $\mathrm{CHA} 1$ & $11.7 \%$ & $45.6 \%$ & $42.7 \%$ & $100.0 \%$ \\
\hline & & $\%$ within $\mathrm{CHA} 3$ & $57.1 \%$ & $39.8 \%$ & $37.8 \%$ & $40.3 \%$ \\
\hline & & $\%$ of Total & $4.7 \%$ & $18.4 \%$ & $17.2 \%$ & $40.3 \%$ \\
\hline & \multirow[t]{4}{*}{ Somehow } & Count & 8 & 68 & 78 & 154 \\
\hline & & $\%$ within $\mathrm{CHA} 1$ & $5.2 \%$ & $44.2 \%$ & $50.6 \%$ & $100.0 \%$ \\
\hline & & $\%$ within $\mathrm{CHA} 3$ & $19.0 \%$ & $28.8 \%$ & $33.5 \%$ & $30.1 \%$ \\
\hline & & $\%$ of Total & $1.6 \%$ & $13.3 \%$ & $15.3 \%$ & $30.1 \%$ \\
\hline \multirow{4}{*}{\multicolumn{2}{|c|}{ Total }} & Count & 42 & 236 & 233 & 511 \\
\hline & & $\%$ within $\mathrm{CHA} 1$ & $8.2 \%$ & $46.2 \%$ & $45.6 \%$ & $100.0 \%$ \\
\hline & & $\%$ within $\mathrm{CHA} 3$ & $100.0 \%$ & $100.0 \%$ & $100.0 \%$ & $100.0 \%$ \\
\hline & & $\%$ of Total & $8.2 \%$ & $46.2 \%$ & $45.6 \%$ & $100.0 \%$ \\
\hline
\end{tabular}

The table 6 considers the relationship between the understandability of the learning materials and the students' relationships with their tutors. The aim of this cross tabulation is to see if there correlation between these two major challenges affecting students of ODL. It is shown that between $30.10 \%$ and $70.40 \%$ of the students have some levels of difficulties understanding the learning materials, while $45.60 \%$ and $91.80 \%$ are not comfortable with their relationship with tutors.

Table 7: Cross Tabulation Showing the Relationship between Level of ICT Deployment and Performance of the Students

\begin{tabular}{|c|c|c|c|c|c|c|}
\hline \multicolumn{6}{|c|}{ Performance Among Students } & \multirow{2}{*}{ Total } \\
\hline & & & No & Some How & Yes & \\
\hline \multirow{9}{*}{$\begin{array}{ll}\text { Level of } & \text { ICT } \\
\text { Deployment } & \end{array}$} & \multirow{3}{*}{ Low } & Count & 16 & 70 & 62 & 148 \\
\hline & & Expected Count & 17.10 & 68.60 & 62.30 & 148.00 \\
\hline & & $\%$ of Total & $3.10 \%$ & $13.70 \%$ & $12.10 \%$ & $29.00 \%$ \\
\hline & \multirow[t]{3}{*}{ Medium } & Count & 28 & 121 & 106 & 255 \\
\hline & & Expected Count & 29.40 & 118.30 & 107.30 & 255.00 \\
\hline & & $\%$ of Total & $5.50 \%$ & $23.70 \%$ & $20.70 \%$ & $49.90 \%$ \\
\hline & \multirow[t]{3}{*}{ High } & Count & 15 & 46 & 47 & 108 \\
\hline & & Expected Count & 12.50 & 50.10 & 45.40 & 108.00 \\
\hline & & $\%$ of Total & $2.90 \%$ & $9.00 \%$ & $9.20 \%$ & $21.10 \%$ \\
\hline
\end{tabular}




\begin{tabular}{|l|r|r|r|r|}
\hline Count & 59 & 237 & 215 & 511 \\
\hline Expected Count & 59.00 & 237.00 & 215.00 & 511.00 \\
\hline$\%$ of Total & $11.50 \%$ & $46.40 \%$ & $42.10 \%$ & $100.00 \%$ \\
\hline
\end{tabular}

Table 7 is a cross tabulation of the level of ICT infrastructure in ODL deployment and the poor performance of students. It is evident that between $42.10 \%$ and $88.50 \%$ are of the opinion that the poor academic performance of the students of the ODL programmes is a major challenge to them especially when compared to the regular classroom-based counterparts even when they feel they do more academic work. Of the $71.00 \%$ of the students who admitted having some fairly high level of ICT infrastructure in their environment, only $8.40 \%$ are of the view that poor level of academic performance in their program do not pose a challenge to them as students and acceptability of the certificates obtained from program in Nigeria. This implies that between $29.90 \%$ and $62.60 \%$ of those with some level of ICT infrastructure in their environment are still facing the poor performance challenges.

Table 8: Test for Significance of the Relationship of Cross Tabulation

\begin{tabular}{|l|r|r|r|}
\hline & Chi-Square Value & f & Asymptotic Significance (2-sided) \\
\hline Pearson Chi-Square & $2.509^{\mathrm{a}}$ & & 0.643 \\
\hline Likelihood Ratio & 2.316 & & 0.678 \\
\hline $\begin{array}{l}\text { Linear-by-Linear } \\
\text { Association }\end{array}$ & 1.239 & & 0.266 \\
\hline N of Valid Cases & 511 & & \\
\hline
\end{tabular}

It is shown from the Pearson Chi-Square that $\mathrm{X}^{2}=2.509, p=0.643$. This shows there is a statistically significant relationship between the level of ICT infrastructure in the domain of the students and their academic performance testing at 5\% level of significance. The result obtained here shows that the level of ICT infrastructure at the reach of the students can to a reasonable extent be related to their level of academic performance more also when most academic work in ODL worldwide is based online with few periods of face-to-face engagements obtainable is some institutions.

\section{Conclusions}

The results obtained in this research shows that the inability of the students to understand the contents of the learning resources can to a reasonable extent be related to their relationship 
with tutors even with other hidden factors playing some roles in this association. When there is little or no cordial relationship between the students and their tutors, coping with some assignments, tutorials and deadlines becomes an issue for the students who ends up feeling frustrated with the entire program. It is also shown that cultivating and maintaining positive cordial relationships between the learners and their facilitators is essential for success in the classroom (Varga, 2017). In addition to this Kirby Hall School (2020) is of the view that adequate relationships between a teacher and his/her students can have a substantial impact on the overall academic success of the learners. When learners view their tutors as a partner rather than an adversary, there are more tendencies for faster comprehension. This will finally reflect on the performance of such students and increased zeal to continue learning. Tyoakaa (2014) in a similar research found that students who have close, positive and supportive relationships with their teachers attain higher levels of achievement than those with more conflicting relationships. It is therefore expected that for students to perform optimally in their academic pursuit, their relationship with the tutors is imperative as it is a major determinant so to how successful they will finally turn out academically.

On the relationship between the level of ICT infrastructure in the students' environment and their academic performance, the study found that there is an association between these two variables. Students who are not privileged to be in an environment with high level of ICT presence have pronounced edge over those who reside in remote areas with limited access. Since most assignments, lectures and interactions take place online, students in areas with low ICT infrastructural levels finds it difficult to catch-up with most tasks. Gikonyo \& Ndiritu (2014) in a similar study in Kenya, observed that adequate ICT infrastructure and support facilities plays substantial roles and are necessary for participation in distance education activities. The researchers suggested that universities participating in distance learning education should of necessity, avail the necessary ICT infrastructure to propel the program as several findings have indicated that availing necessary ICT infrastructure is crucial if adoption of ODL is to be increased in the public universities worldwide.

The result from this study shows that benefits derived from cordial relationship between the students and their tutors cannot be overemphasized. Nicholas et al. (2010) found that the learning experience of students on a distance learning program can be supported by reducing the potentials for isolation. The researchers are of the view that this concept was a problem 
experienced by students and has various direct and indirect influences on their learning experience. This therefore calls for an establishment of a form of learning community, where peer contact is enabled and students are encouraged to share their thoughts with their colleagues and tutors generally. By observing students' activities, their attitude towards study materials and given tasks, a tutor is able to see the students' areas of weakness and area that requires to be improved coupled with the changes that should be implemented for increasing students' interest and involvement in educational process (Zhubreva, 2016). This research shows that those students who have closer relationship with their tutors perform better academically when compared to others. The tutors have to be trained in the area of building strong ties with the learners. Special attention needs to be given to individual students as their needs and backgrounds are diverse. This therefore requires that tutors must develop good mentorship habits and carry students along within academic regulated standards in other to deliver content and achieve positive results. Secondly, the research found that there is a strong relationship between students residing in areas with good ICT infrastructural facilities and their counterparts in the less privileged area. Since ODL is mostly administered via online, investment in infrastructure becomes paramount for the sustainability of the program and its acceptability. Based on the outcome of the tests conducted, it is evident that we reject the null hypothesis and accept the alternative having found that there is a strong relationship between investment in ICT infrastructure and the overall success of the ODL program in Nigeria based on 0.05 level of significance.

\section{Recommendations}

ODL as a system of learning have been accepted worldwide with most countries having distance learning programmes in various tertiary institutions. Mondal \& Das (2015) submitted that most of the students, teachers and administrators who participated in the researcher agreed that distance education was more flexible in terms of access than regular classroom based programmes with lower coursed fees and ease of securing admission. Nigeria is not left out in this tide as the nation cannot effectively fight poverty without drastically reducing the level of illiteracy in the country. Since everyone might not have been privileged to attend classroom-based programmes, the need for ODL has become a means of enabling people to fulfil their educational dreams and aspirations. It therefore becomes imperative that for ODL to thrive in Nigeria, efforts have to be put in place both by government and the institutions mounting ODL programmes since the government alone cannot be blamed for all the problems associated to the smooth riding of ODL 
in Nigeria. The cost of internet access, computing and associated devices have to be drastically regulated and lending institutions can also collaborate with institutions to grant credit to students for the acquisition of required tools to facilitate learning. Faculties operating ODL must ensure continuous training and retraining of tutors in the areas of content delivery, human resources management and learning methods rather than handling ODL students like classroom-based students.

\section{References}

Abdulrahman, J., Imaledo, Opirite B. Peter-Kio, Eme, O. (2012), Pattern of risky sexual behavior and associated factors among undergraduate students of the University of Port Harcourt, Rivers State, Nigeria, Pan African Medical Journal. 2012; 9:97 http://www.panafricanmed-journal.com/content /article /12/97/full/

Adesina, S. (1977), Planning and educational development in Nigeria, Ibadan: Education Industries (Nigeria) Ltd.

COL(2000), An Introduction to Open and Distance Learning, Commonwealth of Learning, http://www.col.org/ODLIntro/introODL.htm (Accessed 15th Aug. 2020)

Edu, M. Sule, S. \& Nsor, E. (2016), Open and Distance Learning (ODL) Education in Nigeria: Challenges of Academic Quality, Journal of Educational Policy and Entrepreneurial Research (JEPER) ISSN: 2408-770X (Print), ISSN: 2408-6231 (Online) Vol. 3, N0.5. 2016. Pp 22-32

Evangelia, K. \& Noel, E. (2019), Students' Learning Characteristics, Perceptions of Small-Group University Teaching, and Understanding Through a "Meeting of Minds", Frontiers in Psychology, Educational Psychology Volume 10| Article 444

Gikonyo, N. \& Ndiritu, A. (2014), ICT Infrastructure: A Key Prerequisite for Adoption of Open and Distance Learning in Public Universities in Kenya, The International Journal of Humanities \& Social Studies (ISSN 2321 - 9203) www.theijhss.com

Hussain, I., Cakir, O., \& Candeğer, Ü. (2018). Social Media as a Learning Technology for University Students. International Journal of Instruction, 11(2), 281-296.

Iloanusi, O. (2007), E-Learning: Its Implementation In Higher Institutions In Nigeria, Nigerian Journal Of Technology, Vol. 26 No.1, March 2007

Isuku, E. (2018), Challenges and Prospects of ICT Facilities in Improving Access to the Open Distance Learning Programme of African Universities: Research Evidence From Nigeria, US-China Education Review A, June 2018, Vol. 8, No. 6, 259-266 doi: 10.17265/2161623X/2018.06.004

Jegede, 0. (2014), Open and Distance Learning Practices in Nigerian Higher Institutions of Learning, $3^{\text {rd }}$ University of Ibadan Annual Distance Learning Centre Distinguished Lecture and Stakeholders' Forum Held at the International Conference Centre, University of Ibadan 
Kanwar, A. \& Cheng, R. (2017), Making Open and Distance Learning Inclusive: The Role of Technology, 6th International Conference on Information and Communication Technology and Accessibility, Muscat, Sultanate of Oman

Karsenti, T. \& Collin, S. (2012). Using IT for Distance Learning : Benefits and Challenges for African Learners. Teachers \& Teaching, 20(2), 9-18. http://dx.doi.org/10.18162/fp.2012. 178

Kirby Hall (2019), The Importance of Positive Teacher-Student Relationships, Improving Academic Success, https://www.kirbyhallschool.org/the-importance-of-positive-teacherstudent-relationships/ (Accessed 20 $0^{\text {th }}$ July, 2020)

Leaders' Perceptions, Journal Of Global Research In Education And Social Science 3(2): 102-111, 2015 International Knowledge Press, www.Ikpress.Org (Accessed May 08 2020)

Modesto, T. \& Gregoriose, B. (2016), Configuration of Open And Distance Learning in New Environments, European Journal of Research and Reflection in Educational Sciences, Vol. 4 No. 4, 2016 ISSN 2056-5852

Nicholas, C., Alice, D. \& Marcus, G. (2010), Overcoming Isolation in Distance Learning: Building a Learning Community through Time and Space, Journal for Education in the Built Environment, 5:1, 27-64, DOI: 10.11120/jebe.2010.05010027

Ogbeide, C. (2019), Challenges Of Open And Distance Learning (ODL) For Functional Education in Nigeria, Journal of Emerging Trends in Educational Research and Policy Studies (JETERAPS) 10(1): 56-61 (C) Scholarlink Research Institute Journals, 2019 (ISSN: 2141 6990), jeteraps.scholarlinkresearch.com

Okoroma, S. (2006), Educational policies and problems of implementation in Nigeria, Australian Journal of Adult Learning, Volume 46, Number 2, July 2006.

Senthil, V. (2018), Does the more internet usage provide good academic grades?. Educ Inf Technol 23,2901-2910 (2018). https://doi.org/10.1007/s10639-018-9749-8 Accessed 15th May, 2020

Situma, D. (2015), Open and Distance Learning and Information and Communication Technologies -Implications for Formal and Non-Formal Education: A Kenyan Case, Journal of learning for Development, JL4D, Vol 2, No 1 (2015)

Tichaona, M. \& Mufuanai, T. (2015), The Efficacy Of Information and Communication Technology (ICT) in Enhancing Quality Open and Distance (Odl) Teaching: Zimbabwe Open University National Centre's Program.

Trading Economics (2018), Nigeria Living Wage Individual 2015-2018 Data https://tradingeconomics.com/nigeria /living-wage-individual. (Accessed $12^{\text {th }}$ June, 2020)

Tyoakaa, L. (2014), Effects of Non-Cordial Relationship between Teachers and Students of Secondary Schools on Teaching-Learning Process, Journal of Research in Education and Society, Volume 5, Number 1, April 2014, ISSN: 2141-675

UNESCO (2002), Open And Distance Learning Trends, Policy And Strategy Considerations, Division of Higher Education, France, http://unesdoc.unesco.org/images/0012/001284/ 128463e.pdf Varga, M. (2017), The Effect of Teacher-Student Relationships on the Academic Engagement of Students, Master thesis, Goucher College 
International Journal of Distance Education and E- Learning (IJDEEL) Volume VI- Issue I (December 2020)

Zhubreva, T. (2016), Distance learning: the practice of intercommunication between a tutor and students, SHS Web of Conferences 29, 02047 (2016), DOI: 10.1051/shsconf/2016, EEIA 2016 